\section{Medicamentos falsificados e contrabandeados no Brasil: panorama geral e perspectivas de combate ao seu consumo}

\author{
Counterfeit and contraband drugs in Brazil: \\ overview and prospects for preventing \\ their use
}

\author{
Medicamentos falsificados e irregulares en Brasil: \\ panorama general y perspectivas para combatir \\ su consumo
}

\author{
1 Agência Nacional de \\ Vigilância Sanitária, Brasília \\ Brasil. \\ 2 Departamento de Polícia \\ Federal, São Paulo, Brasil. \\ Correspondência \\ R. L. Hurtado \\ Agência Nacional de \\ Vigilância Sanitária. \\ SIA trecho 5 área especial 57 \\ lote 600, Brasília, $D F$ \\ 71205-050, Brasil. \\ renato.hurtado@anvisa.gov.br
}

\begin{abstract}
The problem of counterfeit medicines is increasing rapidly, aggravated by globalization and the lure of profit from this illegal activity. Various types of drugs have been counterfeited, posing a serious public health and safety problem. The current article provides an overview of the issue in Brazil and the resulting measures taken by the National Health Surveillance Agency (ANVISA) in collaboration with the Federal Police from 2007 to March 2011. The study analyzed seizures of counterfeit drugs, arrests, and other factors. No professional pharmacist was present in $90 \%$ of the establishments were some type of crime occurred (sale of counterfeit drugs and lack of control of narcotics and other drugs). Among the products seized, most were drugs for erectile dysfunction. The study showed the importance of inter-agency collaboration for combatting this type of irregular drug sales.
\end{abstract}

Counterfeit Drugs; Drug and Narcotic Control; Sanitary Supervision
Renato Lopes Hurtado 1

Marcelo Carvalho Lasmar ${ }^{2}$

\section{Resumo}

O problema de falsificação de medicamentos aumenta a cada dia, acentuado pela globalização e vantagem financeira inerente a essa atividade. Diversos tipos de medicamentos têm sido alvo de falsificações, tornando-se um grave problema de saúde e segurança pública. O estudo avaliou o panorama do problema no Brasil, bem como as ações de fiscalização sanitária realizadas pela Agência Nacional de Vigilância Sanitária em conjunto com o Departamento de Polícia Federal, de 2007 a março de 2011. Foram realizadas análises das apreensões, tipos de apreensões, quantitativos de prisões, entre outros fatores. Observou-se que em $90 \%$ dos estabelecimentos onde ocorreram algum tipo de crime (venda de medicamento falsificado e falta de controle de medicamentos e entorpecentes), não havia a efetiva presença do profissional farmacêutico. Dentre os produtos apreendidos, a maior parte foi de medicamentos para combate da disfunção erétil. Mostrou-se também que a integração entre os órgãos torna-se uma ferramenta de grande valia no combate a esse tipo de venda de medicamento.

Medicamentos Falsificados; Controle de Medicamentos e Entorpecentes; Fiscalização Sanitária 


\section{Introdução}

Segundo a Organização Mundial da Saúde (OMS), um medicamento falsificado é um produto embalado e etiquetado indevidamente, de maneira deliberada e fraudulenta, em que não se respeita sua fonte ou identidade, podendo conter alterações e adulterações em sua fórmula original 1 .

Casos de falsificação mundial aumentaram cerca de $800 \%$ entre os anos de 2000 e 2006. Autoridades estimam 800 mil mortes nesse período em todo o mundo em virtude do consumo desses medicamentos e que $10 \%$ dos medicamentos comercializados são falsificados. Seu crescimento anual é de 13\%, gerando receitas da ordem de 75 bilhões de dólares 2 .

A falsificação de medicamentos e sua comercialização é uma atividade extremamente lucrativa, com risco menor de repressão pelas autoridades policiais em comparação ao tráfico de drogas, estando ligadas diretamente a organizações criminosas internacionais 3 .

A falsificação de medicamentos não se resume a uma classe terapêutica específica. Existem relatos de falsificação de antimaláricos, antibióticos, antineoplásicos, medicamentos para disfunção erétil, entre outros. Os medicamentos mais falsificados no país coincidem com aqueles mais procurados pela população e de maior preço no mercado oficial. Dentre esses, no Brasil constam aqueles de combate à disfunção erétil, anabolizantes, emagrecedores e pílulas de combate ao câncer 4 .

Considerando esses aspectos, propõe-se um estudo visando conhecer a situação de consumo de produtos falsificados e pirateados (medicamentos comercializados no país sem autorização da Agência Nacional de Vigilância Sanitária ANVISA) no Brasil, além de fazer um levantamento de apreensões de medicamentos e quantitativo de prisões a partir dos dados gerados pelas operações da ANVISA e oriundos do Departamento de Polícia Federal (DPF), bem como identificar quais são as irregularidades mais frequentes e possíveis locais do país onde mais ocorrem, verificando quais os fatores de risco associados à ocorrência de crimes dentro do estabelecimento farmacêutico, e ainda propor medidas de minimização desses riscos. O estudo também faz uma descrição do perfil químico dos medicamentos falsificados analisados pela perícia do DPF.

\section{Metodologia}

Em cada operação realizada pela ANVISA em conjunto com as autoridades de polícia judiciária, são registrados em arquivo próprio da agên- cia o local e data onde a mesma foi realizada, o quantitativo de estabelecimentos fiscalizados, a quantidade e o tipo de medicamentos apreendidos, as medidas que foram tomadas, a quantidade de pessoas presas em flagrante, bem como regularidade do estabelecimento frente aos órgãos de vigilância sanitária e Conselho Regional de Farmácia. Os dados gerados são oriundos de apreensões feitas pela ANVISA. A partir desses dados, disponibilizados entre os anos de 2007 e 2011, foi possível fazer um levantamento das irregularidades e locais das apreensões, bem como identificar fatores de risco relacionados à presença de crime no estabelecimento farmacêutico. Esses fatores foram identificados como aqueles de maior frequência e aqueles que apresentam grave risco sanitário.

O grave risco sanitário foi definido como situações de ocorrência de crime dentro do estabelecimento farmacêutico.

As classes terapêuticas dos produtos analisados e ou apreendidos foram determinadas de acordo com a substância declarada no rótulo ou indicada no material de embalagem.

O perfil químico dos medicamentos apreendidos foi obtido através de dados gerados nas análises periciais realizadas pelo DPF. As análises foram realizadas através de cromatografia gasosa em cromatógrafo acoplado com espectrômetro de massas (Hewlett Packard modelo 5890 série I, Ramsey, Estados Unidos) e infravermelho com transformada de Fourier (Thermo Nicolet iS10 FT-IR Spectrometer, Madison, Estados Unidos).

\section{Resultados e discussão}

Foram realizadas 224 operações, totalizando 659 prisões em flagrantes. Dentre os presos, cerca de $70 \%$ são os proprietários dos estabelecimentos inspecionados, $15 \%$ são os farmacêuticos responsáveis técnicos e o restante são outras pessoas envolvidas na atividade criminosa.

Também são casos de prisão em flagrante a comercialização e fabricação dos medicamentos ditos como "naturais", os fitoterápicos sem registro na ANVISA, medicamentos esses de muita aceitação pela população, devido à peculiaridade da cultura popular em acreditar que medicamentos ditos como "naturais" não oferecem risco à saúde. Dentre as operações realizadas, $45 \%$ foram apreensões desses medicamentos, cujas embalagens prometem curas milagrosas para diversas doenças, como câncer, AIDS, hipertensão, atrite, artrose, entre outras. Muitas pessoas consomem esses medicamentos acreditando nas propriedades terapêuticas a eles atribuídas. Além de não terem a comprovação de eficácia 
para essas doenças, muitos são fabricados em locais clandestinos, sem nenhum controle higiênico, acrescentando-se ainda o fato de muitos pacientes abandonarem o tratamento tradicional cientificamente comprovado, migrando para estes tipos de medicamento.

A venda, distribuição, produção e comercialização de medicamentos falsificados e sem registro são condutas tipificadas pelo artigo 273 do Código Penal Brasileiro. Já a venda de medicamentos controlados pela Portaria SVS/MS no 344 , sem autorização da autoridade sanitária, bem como sem respeitar os requisitos legais, infringe os artigos 31 e 33 da Lei no 11.3436 de 23 de agosto de 2006 (lei de drogas), contribuindo para o elevado número de prisões realizadas nas operações supracitadas.

Foi inspecionado um total aproximado de 2.200 locais, sendo 853 (38,72\%) interditados. Desses locais, $64 \%$ foram interditados devido à presença de um ou dois crimes mencionados anteriormente; o restante devido à ausência de alvará sanitário e registro no órgão sanitário, bem como locais sem mínimas condições de higiene ou capacidade de funcionamento satisfatórias.

Foram apreendidos cerca de 115 mil unidades de medicamentos falsos e contrabandeados, 271 mil caixas de medicamentos controlados e 348 toneladas de medicamentos fitoterápicos sem registro na ANVISA. Dentre os medicamentos falsificados, destaca-se a apreensão de medicamentos para o tratamento da disfunção erétil (Cialis e Viagra), responsáveis por $78 \%$ das apreensões. Também foram apreendidos anabolizantes, medicamentos para o tratamento da AIDS e câncer.

Análises químicas realizadas pelo Setor de Perícias do DPF mostram que a variedade de substâncias presentes nesses medicamentos é enorme, divergindo constantemente daquelas declaradas nos respectivos rótulos. Observa-se também rotineiramente a ausência de substâncias farmacologicamente ativas, corroborando os achados da literatura, e principalmente, afetando diretamente a saúde pública.

Dados do DPF mostram que entre janeiro de 2007 e setembro de 2010 foram produzidos 371 laudos de perícia criminal, sendo 610 medicamentos declarados falsos por meio de análises químicas e/ou visuais. Dessas análises, pôde-se observar que em 295 laudos (80\%) foram identificados os medicamentos Cialis e/ou Viagra falsos. Dentre os estados brasileiros, destacam-se Paraná, São Paulo e Santa Catarina, apresentando respectivamente $50 \%, 16,6 \%$ e $6,2 \%$ das apreensões de medicamentos falsificados. Cabe destacar que $69 \%$ desses medicamentos falsificados pertenciam à classe dos inibidores seletivos da fosfodiesterase 5 (Cialis e Viagra), seguidos por $26 \%$ dos esteroides anabolizantes (Durateston, Hemogenin, Deca Durabolin), 3,5\% dos inibidores das prostaglandinas (Cytotec), dentre outros. Outro dado importante é a apreensão conjunta de medicamentos contrabandeados com falsos, sendo que em $49 \%$ das apreensões, esses produtos eram fabricados pela indústria paraguaia, levando a crer que os produtos falsos são produzidos no exterior e adentram no país por meio da fronteira.

Observou-se ainda que não havia a presença do farmacêutico responsável em quase $90 \%$ das farmácias e drogarias nas quais ocorreram as infrações criminais descritas. Na maioria das vezes, esses profissionais só assinavam como responsáveis técnicos e não compareciam efetivamente para trabalhar; em outros, a drogaria ou farmácia era totalmente clandestina, não existindo a presença do profissional farmacêutico.

A Figura 1 mostra a evolução do número de operações e prisões ao longo dos anos de 2007 a 2013. Observou-se uma crescente nos números até o ano de 2010. Em 2010, mesmo com um número menor de operações em relação a 2009, houve maior número de prisões. Em 2011, devido ao corte orçamentário estabelecido pelo governo a toda administração pública federal, houve uma diminuição significativa no número de operações até os dias atuais.

Esse aumento entre 2008 e 2010 se explica pela criação, em dezembro de 2007, do Conselho Nacional de Combate à Pirataria, e a ANVISA fez parte do conjunto de ações decididas por esse conselho, na parte de combate à falsificação de medicamentos. Foi assinado um termo de cooperação entre a ANVISA e a Polícia Federal, permitindo assim maior facilidade e qualidade na execução das operações de combate à venda desse tipo de produto.

As ações foram realizadas nos 27 estados do país e em todos foram encontrados problemas da comercialização de medicamentos falsificados, não sendo "privilégio" de locais menos favorecidos economicamente ou de difícil acesso. Em alguns estados ocorreram em maior número de casos, destacando-se o Paraná.

Pelos dados obtidos, mostrou-se que a presença do profissional farmacêutico é de fundamental importância para evitar que ocorra esse tipo de problema nas farmácias e drogarias do país. Ações de fiscalização mais efetivas por parte dos Conselhos de Farmácia e Vigilância Sanitária local, exigindo e até mesmo interditando os estabelecimentos sem a efetiva comprovação da presença e prestação do serviço do profissional farmacêutico seria de grande valia no combate ao problema. 


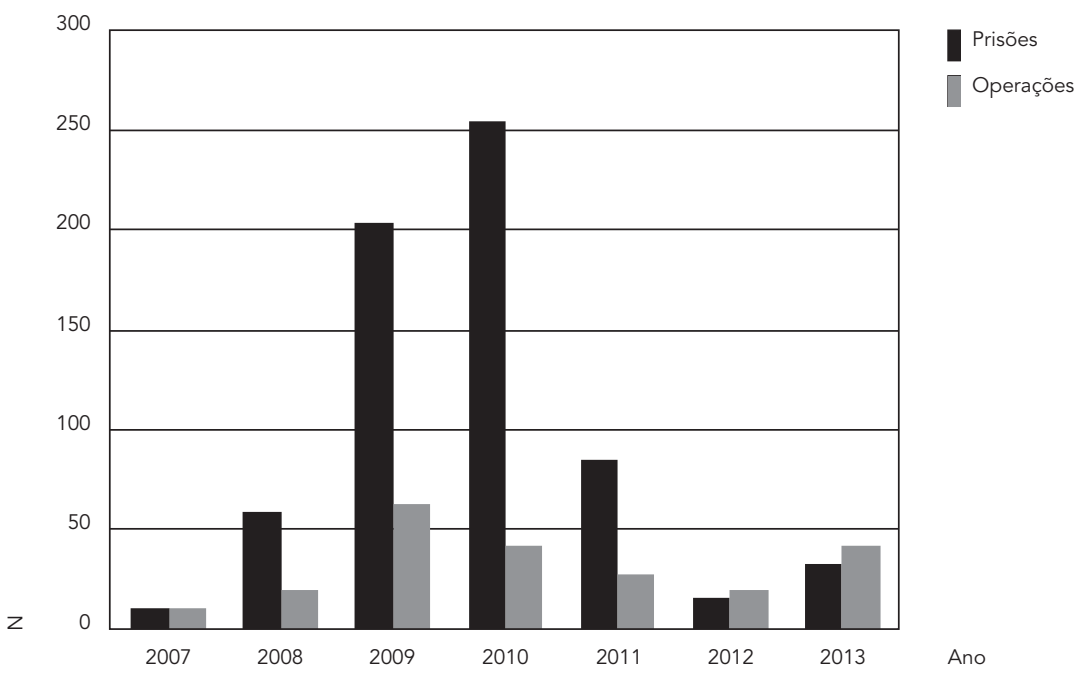

Uma maior cooperação entre os órgãos governamentais mostrou-se como ferramenta bastante efetiva, vide o aumento de ações após a assinatura do convênio entre Polícia Federal e ANVISA.

Maior investimento por parte do governo é necessário para o combate desse problema. O corte orçamentário sofrido pela ANVISA impossibilitou a realização de mais operações, deixando a população mais suscetível ao consumo desse tipo de medicamento. A política de combate implementada pela agência vinha evoluindo e mostrou-se como ferramenta eficaz na erradicação da comercialização dos medicamentos falsificados e contrabandeados.
Profissionais de vigilância sanitária e de saúde têm dificuldade de identificá-los sem um treinamento prévio. Treinamento desses profissionais é uma medida que deve ser adotada em larga escala pela ANVISA. Projetos que preveem a inserção de métodos de rastreabilidade dos medicamentos, possibilitando a rastreabilidade do produto na saída do laboratório, distribuição e venda devem ser implementos o mais rápido possível.

Alertas devem ser feitos sobre o risco de consumo de medicamentos contrabandeados e sem registro no país, bem como sobre o risco de compra de medicamentos em feiras livres e drogarias clandestinas, locais esses onde é alta a probabilidade de se encontrar esse tipo de medicamento. 


\section{Resumen}

El problema de los medicamentos falsificados está aumentando día a día, marcado por la globalización y las ventajas económicas inherentes a esta actividad. Varios tipos de medicamentos han sido objeto de falsificación, convirtiéndose en un grave problema de salud pública. El estudio evaluó el panorama del problema en Brasil, así como la fiscalización sanitaria de la Agencia Nacional de Vigilancia Sanitaria, junto al Departamento de Policía Federal, de 2007 a marzo de 2011. Se realizaron análisis de los tipos de medicamentos falsos y de la cantidad de personas arrestadas. Se observó que en el $90 \%$ de los establecimientos, donde hubo algún tipo de delito (venta de medicamentos falsificados o falta de control de medicamentos y narcóticos), no había presencia efectiva de un farmacéutico. Entre los productos incautados, la mayoría eran medicamentos para combatir la disfunción eréctil. También se demostró que la integración entre los organismos del gobierno se convierte en una herramienta valiosa en la lucha contra este tipo de acción criminal.

Medicamentos Falsificados; Control de Medicamentos y Narcóticos; Fiscalización Sanitaria

\section{Colaboradores}

R. L. Hurtado contribuiu com a análise e coleta de dados e redigiu o artigo. M. C. Lasmar contribuiu com a análise de dados e com a revisão do texto final.

\section{Referências}

1. World Health Organization. Medicines: counterfeit medicines. http://www.who.int/mediacentre/ factsheets (acessado em 01/Ago/2011).

2. Cheng MM. Is the drugstore safe? Counterfeit diabetes products on the shelves. J Diabetes Sci Technol 2009; 3:1516-20.

3. Dubose MM. Criminal enforcement of intellectual property laws in the twenty-first century. Columbia Journal of Law and the Arts 2006; 29:481-4.

4. Ames J, Souza DZ. Falsificação de medicamentos no Brasil. Rev Saúde Pública 2012; 46:154-9.

5. Ministério da Saúde. Portaria SVS/MS no 344, de 12 de maio de 1998. Diário Oficial da União 1998; 15 mai.
6. Brasil. Lei no 11.343, de 23 de agosto de 2006. Institui o Sistema Nacional de Políticas Públicas sobre Drogas - Sisnad; prescreve medidas para prevenção do uso indevido, atenção e reinserção social de usuários e dependentes de drogas; estabelece normas para repressão à produção não autorizada e ao tráfico ilícito de drogas; define crimes e dá outras providências. Diário Oficial da União 2006; 24 ago.

Recebido em 28/Mai/2013

Versão final reapresentada em 31/Dez/2013

Aprovado em 06/Jan/2014 